\title{
What's New in Nutrition Therapy for Cancer Patients
}

\author{
Alessandro Laviano $^{\mathrm{a}}$ Michael Marwan Meguid ${ }^{\mathrm{b}}$ \\ ${ }^{a}$ Department of Clinical Medicine, Clinical Nutrition Unit, Sapienza University of Rome, Rome, Italy; \\ ${ }^{b}$ Surgical Metabolism and Nutrition Laboratory, Surgery, Neuroscience and Physiology, Department of Surgery, \\ Upstate Medical University, Syracuse, N.Y., USA
}

The main goal of nutritional therapy for patients with cancer is to maintain or improve nutritional status sufficiently to allow for the initiation and completion of aggressive anticancer therapies, be this surgery, chemotherapy, radiation therapy or a combination, and further, to increase the patient's functional capacity and quality of life, even in advanced cases. Quality of life is a critical outcome measure in oncology, and the provision of nutrients, either enterally or parenterally in the form of nutritional support, significantly contributes to the preservation of physical function $[1,2]$.

For many years, nutritional therapy for cancer patients has been used cautiously for fear of its hypothetical effect of stimulating tumor growth. This concern has recently been challenged by experimental evidence showing that the sensitivity of tumor cells to calorie restriction is related to specific mutations of the neoplastic cells [3]. Therefore, it is now considered unethical and malpractice to withhold nutritional therapy or withdraw nutritional support from cancer patients in whom the tumor genome has not been analyzed for specific mutations. Clinicians should also consider the clinical relevance of any potential stimulating effect of nutritional therapy, and compare it to the firmly established clinical benefits of nutritional therapy for cancer patients [4].

\section{KARGER}

Fax +4161306 1234

E-Mail karger@karger.ch

www.karger.com
(C) 2011 S. Karger AG, Basel

1011-7571/11/0205-0395\$38.00/0

Accessible online at:

www.karger.com/mpp
It is now becoming widely acknowledged that the first step in multimodal nutritional therapy for cancer pa tients is nutritional counseling. Early, intensive, individualized nutritional counseling has consistently been shown to be effective in preserving body weight and physical function in cancer patients [5-7]. The key to the success of this approach, however, is adherence to patient preferences, which requires the assistance of a well-trained and specialized nutrition/metabolic therapy team, especially considering that energy intake in many cancer patients should be $>30 \mathrm{kcal} / \mathrm{kg}$ of body weight to stop weight loss.

Nutritional therapy may also benefit cancer patients beyond its ability to meet their protein and energy requirements. Indeed, many nutrients have been shown to influence deranged host metabolism during disease when administered at pharmacologic doses. Those nutrients with pharmacologic properties, termed 'nutraceuticals,' are progressively changing the concept of nutritional therapy in oncology towards the practice of metabolic support of cancer patients. The omega-3 fatty acid, eicosapentaenoic acid (EPA), has been shown to have antitumor and anticachectic effects, and the use of oral nutritional supplements enriched with EPA at a dose of 2-3 g/ day may ameliorate lean body mass wasting $[7,8]$. The supplementation of essential amino acids, particularly 
branched-chain amino acids, has been shown to ameliorate cancer anorexia and stimulate protein synthesis, thereby maintaining muscle and lean body mass [9]. Arginine, an immune-modulating amino acid, has recently been demonstrated to improve long-term overall and disease-specific survival in patients with head and neck cancer when administrated as perioperative enteral nutrition [9].

Enthusiasm regarding the pharmacologic effects of selected nutrients should not result in overlooking the primary goal of nutritional/metabolic therapy, especially since there is no 'magic bullet' which will work in cancer patients if energy and protein requirements are not met. Supporting this statement, experimental evidence has shown that in cell cultures, pharmacologic blocking of intracellular proteolytic systems that are hyperexpressed in cancer cachexia cannot suppress protein degradation in the absence of nutrients [10]. Translating this evidence into the clinical setting, meeting energy and protein requirements appears to be a pre-requisite for optimizing the effects of any drug/nutraceutical approach to nurturing cancer patients. More recently, it has been demonstrated that an intact immune system is critical for oncogene inactivation-mediated tumor regression [10]. Therefore, any anti-cancer drug will have suboptimal efficacy in the presence of immune suppression, and since malnutrition is one of the major causes of immune suppression, nutrition is a vital component of anticancer therapies.

\section{Acknowledgments}

Supported in part by a grant from Nutritional Sciences Education and Research Fund, Syracuse, N.Y., USA.

\section{References}

$>1$ Marin Caro MM, Laviano A, Pichard C: Nutritional intervention and quality of life in adult oncology patients. Clin Nutr 2007;26: 289-301.

-2 Laviano A, Meguid MM: Nutritional issues in cancer management. Nutrition 1996;12: 358-371.

3 Kalaany NY, Sabatini DM: Tumours with PI3K activation are resistant to dietary restriction. Nature 2009;458:725-731.

4 Lundholm K, Daneryd P, Bosaeus I, Körner $\mathrm{U}$, Lindholm E: Palliative nutritional intervention in addition to cyclooxigenase and erythropoietin treatment for patients with malignant disease: effects on survival, metabolism, and function. Cancer 2004;100: 1967-1977.

5 Kirchner H, Laviano A, Meguid MM: Diagnose and treat, but start nutritional/metabolic supportive therapy at the same time! J Support Oncol 2007;5:2-4.
6 Meguid MM, Gonçalves CG: Message to surgeons: the expected norm in elective complex GI cancer surgery is use of perioperative immunonutritional therapy that also saves hospital costs! Ann Surg 2009;249: 364-365.

7 van den Berg MG, Rasmussen-Conrad EL, Wei KH, Lintz-Luidens $\mathrm{H}$, Kaanders JH, Merkx MA: Comparison of the effect of individual dietary counseling and of standard nutritional care on weight loss in patients with head and neck cancer undergoing radiotherapy. Br J Nutr 2010;104:872-877.
$>8$ Fearon KC, von Meyenfeldt MF, Moses AG, Van Geenen R, Roy A, Gouma DJ, Giacosa A, Van Gossum A, Bauer J, Barber MD, Aaronson NK, Voss AC, Tisdale MJ: Effect of a protein and energy dense N-3 fatty acid enriched oral supplement on loss of weight and lean tissue in cancer cachexia: a randomized double blind trial. Gut 2003;52:1479-1486.

9 Laviano A, Muscaritoli M, Cascino A, Preziosa I, Inui A, Mantovani G, Rossi-Fanelli F: Branched-chain amino acids: the best compromise to achieve anabolism? Curr Opin Clin Nutr Metab Care 2005;8:408-414.

-10 Rakhra K, Bachireddy P, Zabuawala T, Zeiser R, Xu L, Kopelman A, Fan AC, Yang Q, Braunstein L, Crosby E, Ryeom S, Felsher DW: CD4+ T cells contribute to the remodeling of the microenvironment required for sustained tumor regression upon oncogene inactivation. Cancer Cell 2010;18:485-498. 